\title{
PLL and Current Mode Control Design Methodologies Applied to Improve the Performance of a Grid-Tie Photovoltaic System
}

\author{
Marenice Melo de Carvalho* \\ Renan Landau Paiva de Medeiros* Iury Valente de Bessa* \\ Florindo A.C. Ayres Junior* Rafael da Silva Mendonça* \\ * Faculdade de Tecnologia, Universidade Federal do Amazonas, AM \\ E-mails: \{marenice, renanlandau, iurybessa, florindoayres, \\ mendoncarms\}@ufam.edu.br
}

\begin{abstract}
:
Currently, several forms of electric generation have been investigated, one of the most promising being the photovoltaic system. These systems produce electricity in DC format and the electrical networks in AC format, being necessary to use DC-AC converters to make the connection between the photovoltaic source and the conventional grid. For this work, it is proposed to use the current mode control and the Phase-Lock-Loop (PLL) to ensure the synchronization of the connection of the photovoltaic panels in the network. In both controllers, PI control structures are used. In the PLL the gains are obtained by the Roots Locus method and CHR method and the Current Mode Control the gains were obtained by the poles and zeros cancellation method. Finally, simulations were performed for panel irradiance variation, and also for temperature variation. For voltage sag in the PLL controller and reference change for the operation of the Current Mode control.
\end{abstract}

Keywords: Renewable energy, DC/AC power converters, Current Mode Control, Phase-Locked Loop.

\section{Introduction}

Currently, thermoelectric plants are the second largest source of energy in Brazil, losing only to hydroelectric plants, which produce energy in AC (Barroso, 2016). These type of sources are polluting, causing a negative impact on the environment (Tolmasquim, 2016). However, there are non-polluting sources in its generation and also considered renewable, such as solar panels that produce energy with DC current (Villalva and Gazoli, 2012), and need to be converted into $\mathrm{AC}$ to allow a more extensive use, allowing the connection of these systems to the system conventional electric

The voltage inverters are the types of equipment responsible for transforming the constant output of the solar panel into an alternating signal. They work from a set of semiconductor devices of high power, such as IGBT, which has the function of switching repeatedly. Thus, a sinusoidal function is obtained at the output of a constant signal at the input (Barbi and Martins, 2008)(Hart, 2011). To connect the output of the inverter to the network, the parameters such as phase, amplitude, and frequency of the network are very important and are used as a reference for the connection. Thus a phase tracking system is required for system synchronization (Nicastri and Nagliero, 2010).

Current control techniques for voltage inverters applied to grid-connected renewable sources have already been investigated as shown in (Parvez et al., 2016) and (Paikray et al., 2017) that present a review on linear and nonlinear control for voltage inverters and three-phase gridconnected renewable power sources. In (Yao et al., 2015), an improved control strategy is proposed for the threephase grid-connected inverter with space vector pulsewidth modulation (SVPWM). In (Azmi et al., 2017), it presents a control strategy that uses the number of feedback loops to allow fast and accurate tracking of the desired set points with the small of overshoot.

The inverter has a significant role in solar energy systems since the interconnected use of the grid can cause some problems for the utility, such as the loss of coordination in protection systems due to overcurrent, undue action of instant reclosures and islanding operations (Júnior, 2013). Different from the other works, this one uses a mathematical model of the photovoltaic system for the input of the inverter. Where the voltage variation is considered according to the temperature and irradiance levels of the solar panel. PLL controller was implemented as in (Yao et al., 2015)(Azmi et al., 2017) to perform the synchronism of the signal generated by the converter and the electric network. And also control in the current mode as in (Yao et al., 2015) to perform control of the power flow transferred to the output.

The rest of this paper is organized as follows: Section 2 is address the theoretical aspects for the development of the 
work; Section 3 addresses the methodological procedures in this work; Section 4 presents the results of the proposed analyzes, finally, Section 5 presents the main conclusions of the study.

\section{Background}

\subsection{Concepts on solar panels}

Solar panels are devices used to convert energy from the Sun into electrical energy due to the photovoltaic effect. In these devices, the output parameters are the voltage and current and the input parameters are the irradiance and the temperature. Where the irradiance is the level of radiation per square meter that reaches the surface of the soil. The level of these input variables defines what the output response of the panels will look like. (Rekioua and Maragne, 2012).

In (1), it is presented the mathematical model that describes the dynamics of the photovoltaic panel.

$$
I_{p v}=I_{p h}-I_{o}\left(e^{\frac{V_{d}}{n V_{T}}}-1\right)-\frac{V_{p v}+R_{s} I_{p v}}{R_{s h}}
$$

where, $I_{p v}$ is the output current; $I_{p h}$ is the photocurrent, or current generated; $I_{O}$ is the diode saturation current; $V_{d}$ is the voltage in the diode; $n$ is the factor of ideality; $V_{T}$ is the thermal stress; $V_{p v}$ is the output voltage; $R_{s}$ is the series resistance of the solar cell and $R_{s h}$ is the shunt resistance.

The irradiance level and the output current are directly proportional. The temperature level and the output voltage are inversely proportional. such as the temperature and output voltage level. Thus, for greater output power supply the irradiance must be high while the temperature must be low. (Villalva and Gazoli, 2012).

\subsection{Voltage inverter}

The DC-AC voltage converter has an alternating output signal with the null mean value. This signal can be generated from a constant independent source such as solar panels (Barbi and Martins, 2008). The conversion of the DC signal is performed from two modulating signals, $m_{d}$, and $m_{q}$, which are constant quantities that are made up by the three sine-wave modulation indexes $m_{a}, m_{b}$ and $m_{c}$. Such transformation is performed using the inverse Park's transformation.

\subsection{Mathematical Model}

This work is based on the system presented in Fig. 1. The $V_{d c}$ input comes from a more detailed model of the PV system, which relates the $V_{d c}$ output to the irradiance and temperature inputs. Particularly, the dynamics of the inverter is more relevant to this work since it is employed to design the controllers.

The mathematical model of the converter presented in (2) is based on the average three-phase converter model, since it is possible to describe the relationship between the output dynamics of the inverter and the modulation signals used (Yazdani and Iravani, 2010).

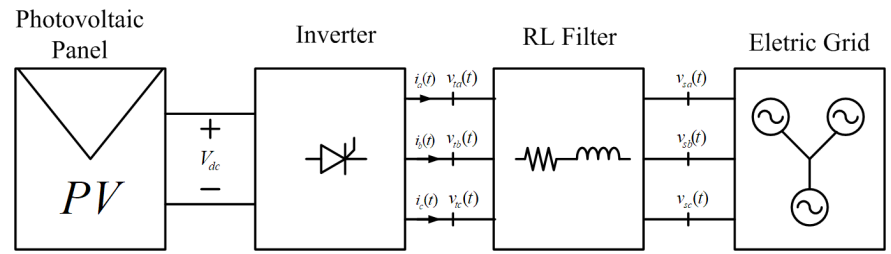

Fig. 1. Diagram of the analyzed circuit connection.

$$
v_{t a}=\frac{V_{d c}}{2} m_{a} ; v_{t b}=\frac{V_{d c}}{2} m_{b} ; v_{t c}=\frac{V_{d c}}{2} m_{c}
$$

The inverter is connected to the standard grid via an $\mathrm{RL}$ filter. This connection can be represented by (2), as shown in the schematic diagram of Fig. 1.

$$
G(s)=\frac{1}{L s+R}
$$

This equation is enough to put into practice the control techniques applied in the inverter. The converter is connected through an RL filter to the standard power grid. As shown in the schematic diagram of Fig. 1. To ensure the phase and frequency synchronism of the signal generated by the converter with the mains, it is necessary to develop the Phase-Locked Loop subsystem. Its purpose is to ensure the phase and frequency adjustment of the voltage inverter with the network, using a PI-structure controller, as shown in (4). The control of the powers transferred to the electric network is realigned through the control in current mode. Using a PI control structure, such as that presented by (4).

$$
C(s)=\frac{k_{p} s+k_{i}}{s}
$$

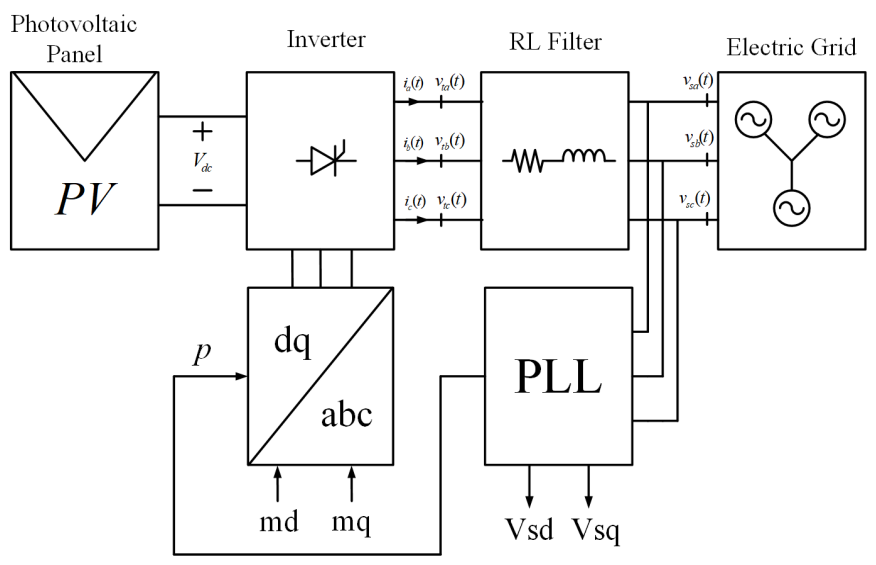

Fig. 2. PLL block diagram.

\subsection{Phase-Locked Loop (PLL)}

The PLL controller is a device that tracks one signal from another. It keeps the output signal synchronized with a reference signal (Hung, 1996). It consists of three stages, a phase detector (PD), a loop filter (LF) and a voltage control oscillator (VCO). The PD makes a signal difference between the output signal and the null input $\rho=\omega_{0} t+$ 
$\theta_{0}$. The error signal then passes through an LF. It then triggered a VSO to generate the output signal (Nicastri and Nagliero, 2010).

\subsection{Current control}

A controller in current mode controls the active and reactive powers supplied to the power grid. They protect the systems against overcurrent, and also to have an advantage of better dynamic performance and greater control accuracy (Yazdani and Iravani, 2010). The block diagram of the control system is shown in Fig. 2. The controller is included in the system as shown in the block diagram of Fig. 2. The current mode control is made from the quadrature axis currents $i_{q}$ and direct $i_{d}$ of the system, fed by the voltage components $V_{s d}$ and $V_{s q}$. The system is decoupled into two structures, allowing each compensator to be performed independently. Considering that $K_{d}$ and $K_{q}$ are the two controller structures of type PI, designed with the purpose of increasing the speed of the system response and guaranteeing null error of permanent regime. The structures $K_{d}$ and $K_{q}$ are obtained by the same method, being equal, each applied on its axis.

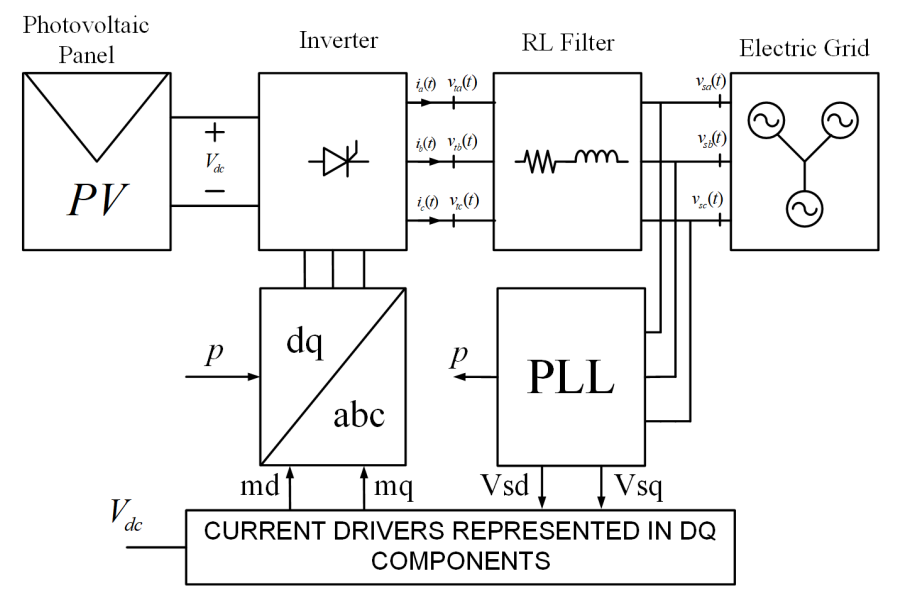

Fig. 3. Block diagram of the PLL controller and control in current mode.

3 Control design methodologies for grid-connected photoltaic systems

\subsection{Experimental Environment}

The simulations are performed in the Matlab/Simulink environment with the fixed-step size of $10^{-4}$ and solver ode4 (Ruge-Kutta).

\subsection{Description of Controllers}

The structure of the first control system is organized according to Fig. 2 only with the implementation of the PLL controller. Using MATLAB to find the gains of the controller, with the Root Locus (RL) method (D'Azzo and Houpius, 1975), considering the control structure of type PI and later using CHR method (Pinto, 2014).
Gains obtained using the Root Locus method are shown in Table 2. Their values are reached for maximum overshoot of $5 \%$ and settling time of $100 \mathrm{~ms}$.

Table 2 also presents the gains obtained with the empirical method CHR, developed by K.L. Chien, J.A. Hrones and J.B. Reswick. Their values are found according to table 1 to meet the fastest response criteria and $0 \%$ overshoot. Using $\mathrm{K}=10, \theta=0.001$ and $\tau=1.375$.

Table 1. CHR tuning table, no overvaluation

\begin{tabular}{cccc}
\hline controller & $K_{p}$ & $T_{i}$ & $T_{d}$ \\
\hline $\mathbf{P}$ & $0.3 \tau / \mathrm{K} \theta$ & - & - \\
PI & $0.35(\tau / \mathrm{K} \theta)$ & $1.16 \tau$ & - \\
PID & $0.6 \tau / \mathrm{K} \theta$ & $\tau$ & $\theta / 2$ \\
\hline
\end{tabular}

To get the gains the controller in current mode can be used pole cancellation since the poles of the system are situated in the left half-plane of the complex plane. In (5) the characteristic equation is shown with the pole of the system to be canceled, $p_{1}=(R / L)$, where line resistance and inductance output filter. Also with a pole in $p_{2}=1 / \tau_{i}$, where $\tau_{i}$ is the time constant in closed loop. Inserted so that the drivers are tuned.

Observing the pole to be canceled, as presented in (5).

$$
\Delta_{d}(s)=\left(s+\frac{R}{L}\right)\left(s+\frac{1}{\tau_{i}}\right)
$$

The development of the equation results in:

$$
\Delta_{d}(s)=s^{2}+\left(\frac{R}{L}+\frac{1}{\tau_{i}}\right) s+\frac{R}{L \tau_{i}}
$$

The characteristic equation is presented in (7).

$$
\Delta_{c}(s)=1+C G
$$

Substituting (3) and (4) into (7), has:

$$
\Delta_{c}(s)=s^{2}+\left(\frac{k_{p}}{L}+\frac{R}{L}\right) s+\frac{k_{i}}{L}
$$

Comparing (6) and (8), where the pole cancellation occurs, we get the results of the values of the controller gains in (9)

$$
K_{p}=\frac{L}{\tau_{i}} ; \quad K_{i}=\frac{R}{\tau_{i}}
$$

For $R=1,63 \mathrm{~m} \Omega$ e $L=100 \mu \mathrm{H}$ e $\tau_{i}=1 \mathrm{~ms}$, we have the values of the gains in table 2 .

Table 2. $K_{p}$ and $K_{i}$ gains from the drivers.

\begin{tabular}{cccc}
\hline Parameters & PLL & PLL & Current Mode \\
\hline Method & CHR & Root Locus & Pole Cancellation \\
$k_{p}$ & 48.2 .5 & 117.6 & 0.10 \\
$k_{i}$ & 30.2 & 5538.8 & 1.63 \\
\hline
\end{tabular}




\subsection{Description of experiments}

The first set of experiments checks the performance of the inverter for the variation of the parameters of temperature and irradiance of the solar system. Keeping the temperature set at $25^{\circ} \mathrm{C}$ the irradiance is varied from $600 \mathrm{~W} / \mathrm{m}^{2}$ to $1200 \mathrm{~W} / \mathrm{m}^{2}$. The irradiance is then maintained at $1000 \mathrm{~W} / \mathrm{m}^{2}$ and the temperature varied from $30^{\circ} \mathrm{C}$ to $90^{\circ} \mathrm{C}$.

For the PLL controller, the outputs of the voltages in the direct and quadrature axis of the model were observed, and a voltage sink was inserted in one of the phases of $V_{s}$, with this it is possible to verify the effect of this sinking in the performance of the PLL. A comparison of the PLL input and output signal is also presented.

For the fourth experiment, a step variation was performed in $85.5 \mathrm{~s}$ and $85.7 \mathrm{~s}$ in the $I_{d}$ reference with a variation of $0.7 \mathrm{p} . \mathrm{u}$. to $0.5 \mathrm{p} . \mathrm{u}$., then in the time of $85.9 \mathrm{~s}$ a new variation of $0.25 \mathrm{p} . \mathrm{u}$. in the reference of $I_{q}$, considering an accommodation time constant of $5 \mathrm{~ms}$. A disturbance was also introduced, aiming to check the performance of the system with the controls in the current mode. Fig. 3 shows the diagram with all system controllers.

\section{Experimental evaluation}

From the mathematical models presented, in the mentioned simulation environment, it is possible to get the following results.

\subsection{Test 1: Voltage for irradiance and temperature vari- antion}

The first test was done for the variation of the irradiance at the entrance of the photovoltaic panel. Observing how the RMS output of the inverter behaves for each level of irradiance.

The analysis time is the 90 s due to the time the panels take to reach their largest value, estimated at $1450 \mathrm{~V}$ DC. After the transient period, the irradiance change changes the voltage level of the inverter output. This result is expected since the irradiance influences the current levels. According to Fig. 4

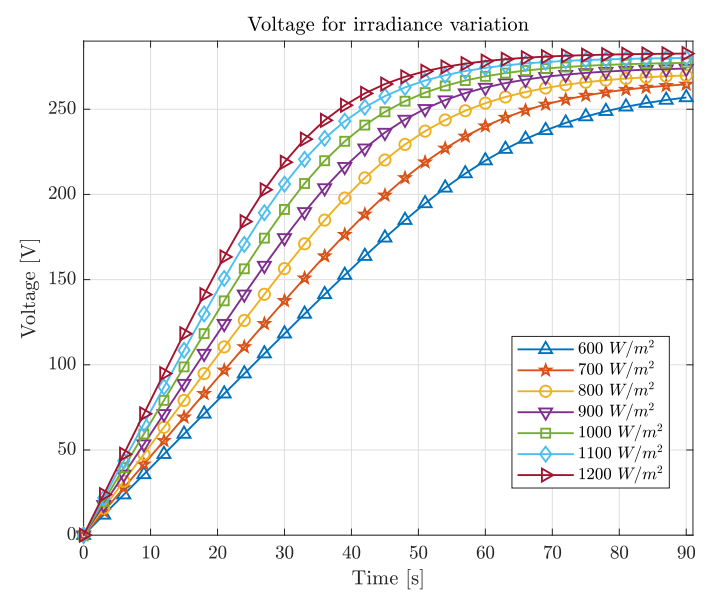

Fig. 4. RMS Voltage for irradiance variation.
The second test was done for the variation of the temperature at the input of the photovoltaic panel. Observing how the RMS voltage output of the inverter behaves for each level of temperature.

For this variation, the higher the temperature level the lower the voltage level at the inverter output. This is because the voltage is proportional to the temperature. After the transient period, this effect can be observed in the system, as shown in Fig. 5.

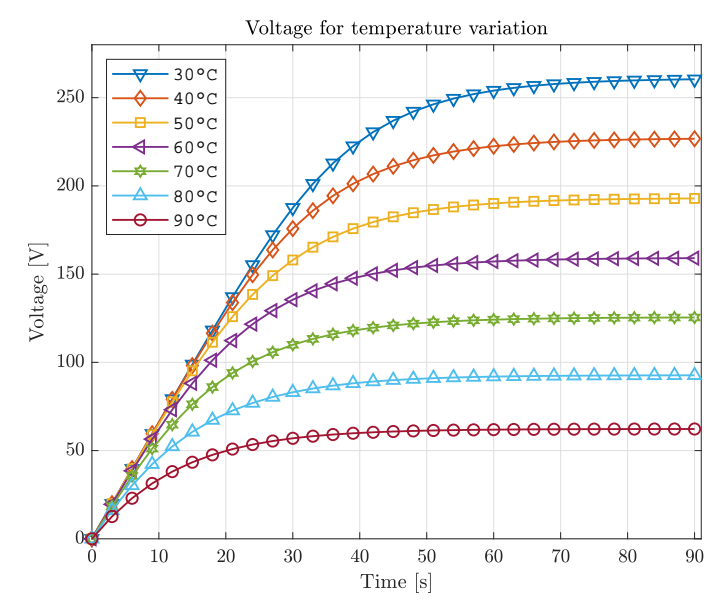

Fig. 5. Voltage RMS for temperature variation.

\subsection{Test 2: Voltage sag}

In this test, a voltage sink of $10 \%$ between the $0.2 \mathrm{~s}$ and $0.3 \mathrm{~s}$ times in the network bus was used to check PLL performance.

Fig. 6a shows the output voltage output $V_{s}$ on the direct and quadrature axes of the PLL controller, for the gains found with the RL method and the CHR method.

Both results have the desired settling time of $100 \mathrm{~ms}$. Only the results obtained with the CHR method presented overshoot less than $5 \%$

Fig. $6 \mathrm{~b}$ shows the result for the output with voltage sag. It can be observed that the specifications of the controller keep met, it is fast and there is overshoot apenas no resultado obtido com o RL method. Even with an oscillation, the controller can return to the reference after the voltage sag.

The Fig. 7 also shows the frequency of the controller for a voltage sag between $0.2 \mathrm{~s}$ and $0.3 \mathrm{~s}$. The output exhibits an oscillation in the time when voltage sag occurs. The amplitude of the oscillation was smaller when tuning with the CHR method was used.

\subsection{Test 3: Comparison of the input and output signal defense of the PLL}

The input signal of the PLL controller is the signal of the infinite bus, as shown in the block diagram of Fig. 3.

The input and output signal of the PLL controller is shown in Fig. 8a and 8b In these images, it is seen that the output of the controller is in phase with the input. Keeping the 
gap of approximately $120^{\circ}$ between phases. Table 3 shows the value of the lags.

Table 3. Angles.

\begin{tabular}{ccc}
\hline Angle & Input & Output \\
\hline$\theta_{A B}$ & $118.80^{\circ}$ & $118.80^{\circ}$ \\
$\theta_{B C}$ & $120.96^{\circ}$ & $120.96^{\circ}$ \\
$\theta_{C A}$ & $118.80^{\circ}$ & $118.80^{\circ}$ \\
\hline
\end{tabular}

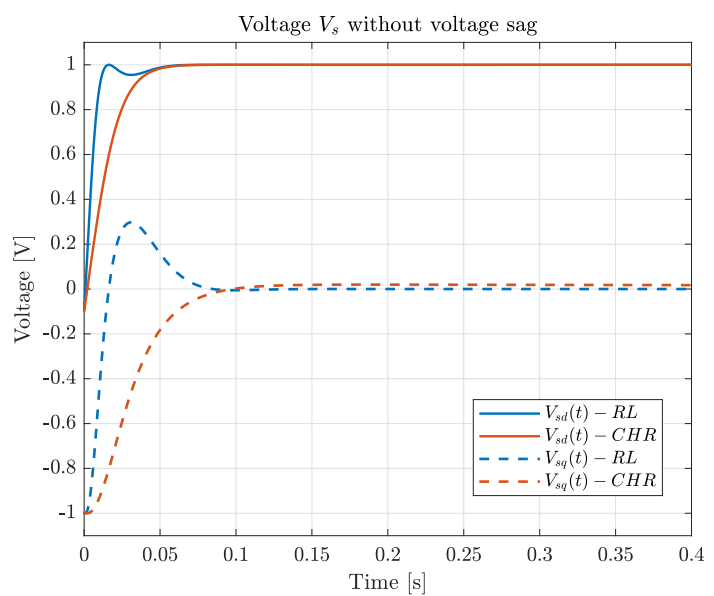

(a)

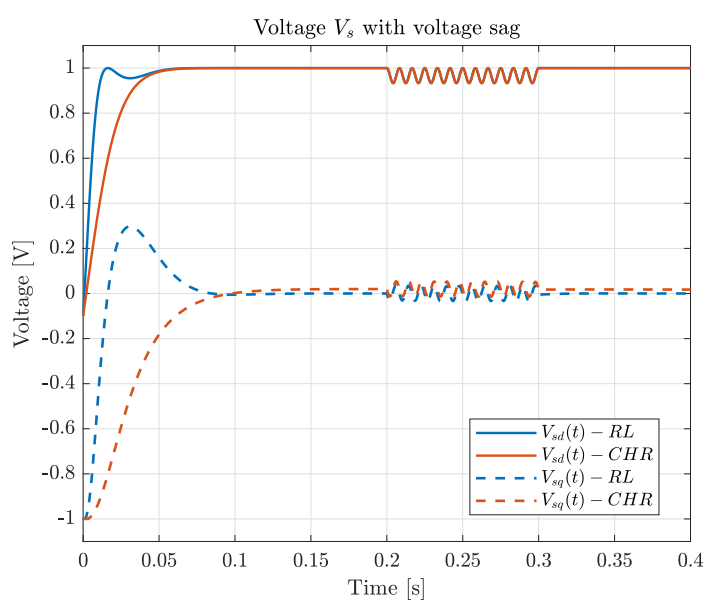

(b)

Fig. 6. $V_{s}$ voltages at p.u. of the PLL controller output.

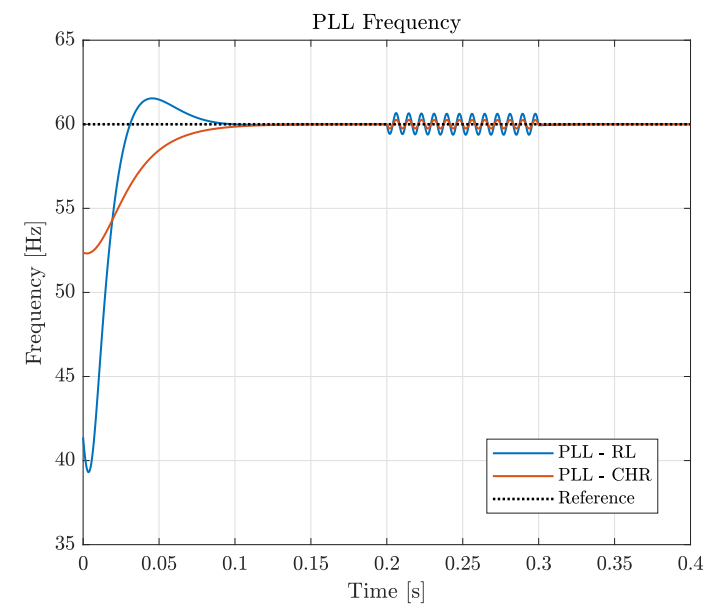

Fig. 7. PLL frequency with voltage sag.

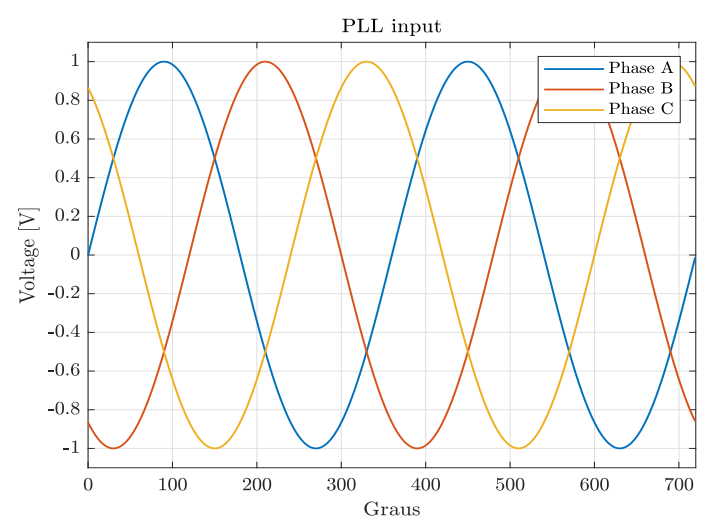

(a)

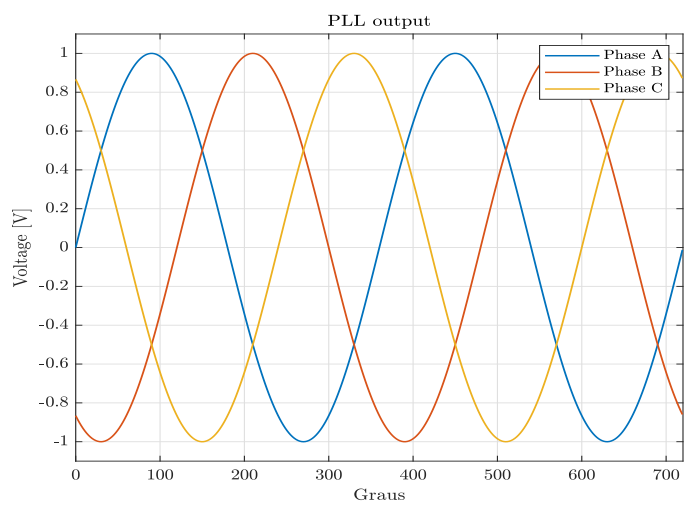

(b)

Fig. 8. $V_{s}$ voltages at p.u. of the PLL controller input and output.

\subsection{Test 4: Power flow transfer}

The response of the current mode controller is shown in Fig. 9. It shows the behavior of the reference currents $I_{q}$ and $I_{d}$ and the current dynamics when there is a change in their respective references.

To evaluate the performance of the controller, a reference variation step was inserted at the times $85.5 \mathrm{~s}$ and $85.7 \mathrm{~s}$ for the current $I_{d}$, where the current values varied from 0.7 p.u. to 0.5 p.u. and 0.5 p.u. to 0.9 p.u., respectively, then the variation of $I_{q}$ with variation from 0 to $0.25 \mathrm{p} . \mathrm{u}$. in $85.9 \mathrm{~s}$. These high times are after the transient of the system. This is because the panels take a long time to reach their maximum value, as can be seen in test 1 . It can be observed that for each current variation, Fig. 9, the power flow transferred from the converter to the electric grid also varies, as shown in Fig. 10.

In Fig. 9 one can observe the compensation of all the reference variations of the direct and quadrature axis currents, it is worth mentioning that the controller has met the performance requirements demanded.

However, the power flow adjustment occurs as the current references change, however, the power controller has not yet achieved the desired performance, requiring adjustments for its proper operation, since the power output error is high. 


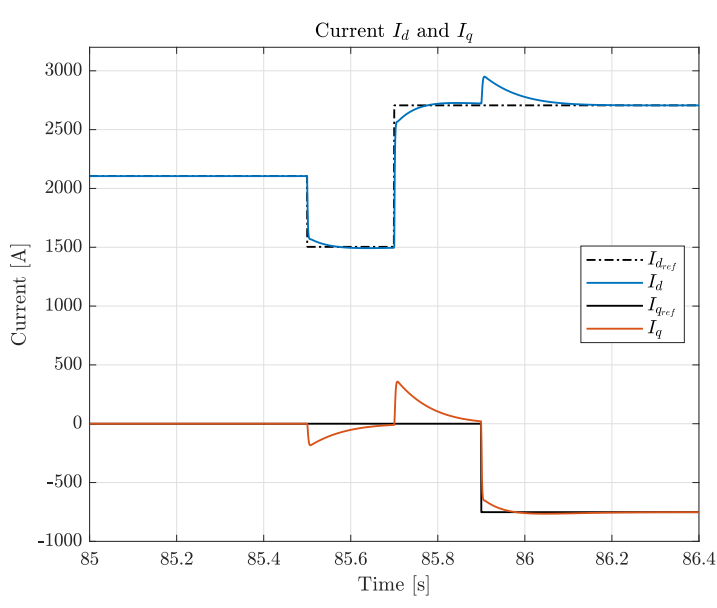

Fig. 9. Direct and quadrature axis currents.

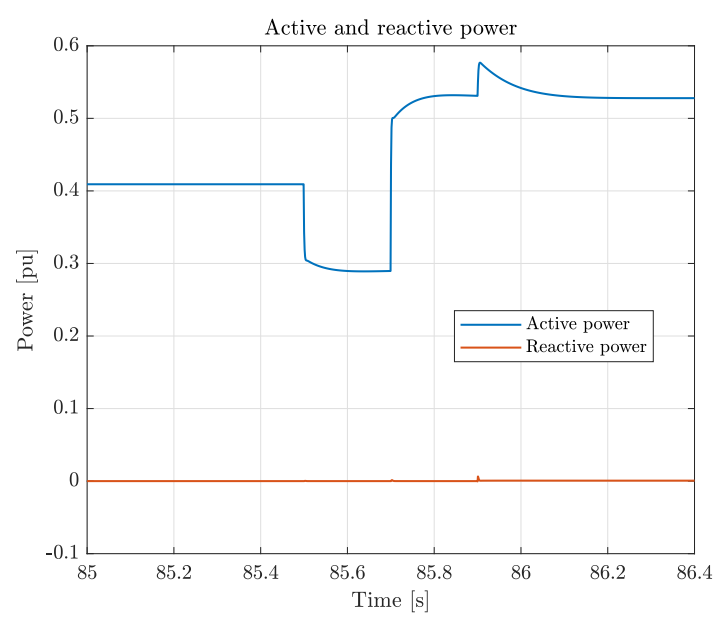

Fig. 10. Active and Reactive Power.

\section{Conclusions}

It was proposed the use of controllers to improve the performance of voltage converters connected to an infinite bus, fed by a set of photovoltaic panels. Controls evaluated were PLL and control in current mode. Both are structured in proportional and integral type controllers. The variation of the output of the converter for variation of irradiance and temperature occurred as expected.

The gains were obtained by the root locus methods, CHR method and cancellation of poles and zeros. For the PLL controller the best results were obtained with the CHR tuning method. With this, it has been observed that with the inclusion of the controllers the performance of the converter can be improved according to the desired specification, the PLL fulfills that expected by maintaining the synchronism of the output signal with the reference signal, that is the local network and the current mode controller adjusts the output power flow to the output from a current.

\section{Acknowledgments}

This work had the financial support of the project QUALIPIM-CAP: Human Resources Training for Manaus Indus- trial Pole in automation and optimization of industrial processes and production, under the Priority Project of Human Resources Training - SUFRAMA/CAPDA, Fundação Muraki.

\section{References}

Azmi, S., Tajuddin, M.F.N., F. Mohamed, M., and J. Hwai, L. (2017). Multi-loop control strategies of three-phase two-level current source inverter for grid interfacing photovoltaic system. 277-282.

Barbi, I. and Martins, D.C. (2008). Introdução ao estudo dos conversores $C C$-CA (in Portuguese). Ed. Florianópolis: Ed dos Autores.

Barroso, L.A. (2016). Anuário Estatístico de Energia Elétrica (in Portuguese). Empresa de Pesquisa Energética. Ministério de Minas e Energia.

D’Azzo, J.J. and Houpius, C.H. (1975). Análise e Projeto de Sistemas de Controle Lineares (in Portuguese). Editora Guanabara Dois.

Hart, D.W. (2011). Power Eletronics. McGraw Hill.

Hung, J. (1996). Phase-locked loop techniques. a survey. IEEE Transactions on Industrial Electronics, 43(6), $609-615$.

Júnior, H.G. (2013). Estudo de controladores aplicados a inversores para UPS com operação ilhada (in Portuguese).

Nicastri, A. and Nagliero, A. (2010). Comparison and evaluation of the PLL techniques for the design of the grid-connected inverter systems. 3865 - 3870. doi: 10.1109/ISIE.2010.5637778.

Paikray, P., Swain, S.C., Dash, R., and Panda, P.C. (2017). A review on current control techniques for inverter for three phase grid connected renewable sources. In 2017 Innovations in Power and Advanced Computing Technologies (i-PACT), 1-6. doi:10.1109/IPACT.2017. 8245203.

Parvez, M., Elias, M.F., Abd Rahim, N., and Osman, N. (2016). Current control techniques for three-phase grid interconnection of renewable power generation systems: A review. Solar Energy, 135. doi:10.1016/j.solener.2016. 05.029 .

Pinto, J.E.M.G. (2014). Aplicação Prática do Método de Sintonia de Controladores PID Utilizando o Método do Relé com Histerese (in Portuguese).

Rekioua, D. and Maragne, E. (2012). Optimization of Photovoltaic Power Systems Modelization. Editora Springer.

Tolmasquim, M.T. (2016). Energia Renovável Hidráulica, Biomassa, Eólica, Solar, Ocêanica (in Portuguese). Empresa de Pesquisa Energética. Ministério de Minas e Energia.

Villalva, M.G. and Gazoli, J.R. (2012). Energia Solar Fotovoltaica - Conceitos e Aplicações - Sistemas Isolados e Conectados À Rede (in Portuguese). Editora Érica, $1^{\circ}$ edition.

Yao, Z., Xiao, L., and Guerrero, J.M. (2015). Improved control strategy for the three-phase grid-connected inverter. IET Renewable Power Generation, 9(6), 587592. doi:10.1049/iet-rpg.2014.0350.

Yazdani, A. and Iravani, R. (2010). Voltage-Sourced Converters in Power Systems: Modeling, Control, and Applications. Wiley-IEEE Press. 